\title{
Dentists' Knowledge, Attitude and Behavior towards the Dental Ergonomics
}

\author{
Dr. Karibasappa G.N, Dr.Sujatha Anandan, Dr. Rajeshwari K. \\ Associate Professor, Department of Public Health Dentistry, ACPM Dental College, Dhule-424001, \\ Maharashtra, India. \\ Reader, Department of Public Health Dentistry, Sathyabama Dental College and Hospital, Chennai-600012, \\ Tamil Nadu, India \\ Post graduate, Department of pathology, ACPM Medical College and Hospital, Dhule-424001, Maharashtra, \\ India.
}

\begin{abstract}
:
Background: The prevalence of the work -related musculoskeletal disorders among the dentist is high. Ill health retirement adds on the burden to the health care delivery system. Numerous studies have been conducted to assess the work related disorders but limited data is available on the knowledge, attitude and behavior during dental health care among the Indian dentist.

Materials and Methods: The questionnaire survey was carried out among 55 Indian dentists aged between 24 to 46 years, from Dhule, India. The questionnaire related to knowledge, attitude and behavior related to ergonomic practices in the dental office. Data were statistically analyzed applying chi-square test ( $p<0.05)$.

Results: The total sample consists of 40 males and 15 females. Out of total 55, 44\% are MDS and 56\% are BDS graduates. There is a significant difference between knowledge, attitude and behavior among dentist $(p<0.05)$.Around $53 \%$ dentist worked for $6-8$ hours and $45.4 \%$ adopted sitting posture and $43.6 \%$ adopted the combination of sitting and standing position. The main work related musculoskeletal disorder symptoms included pain in Back, Neck and shoulder region.

Conclusion: MDS graduates had better knowledge, attitude than BDS graduates towards dental ergonomics. Increase in knowledge and attitude didn't result in the desired behavior. Female MDS had adopted better ergonomic principles. Motivation and encouragement to adopt the dental ergonomics helps to prevent the work related musculoskeletal disorders.
\end{abstract}

\section{Introduction}

Human being survival is dependent on proper intake of food and adopting healthy life styles. Occupation gives secure life and organizes behavior. Dentistry is a profession where clinically, operational skill is restricted to an area covering only a few tens of millimeters (the mouth) and requires repeated, precise force application while delivering oral health. These situations demand a fixed posture that can create occupation hazards for dentist.

The term Ergonomics has been derived from Greek word 'Ergo' mean work and 'nomic' means natural loss to create a word that the science of work and a relationship to that. Ergonomics is defined as a set of multidisciplinary knowledge applied to the organization of labor activity that makes up a job. The goal of ergonomics is to stabilize a safe, healthy and comfortable working environment, thereby preventing health problem and improving productivity. ${ }^{1}$ If ergonomic principles are applied in the field of dentistry, it helps to reduce cognitive and physical stress, prevent occupational hazards', thus, helps to improve productivity and more comfort to the dentist and patient. ${ }^{2}$

Worldwide increased awareness among population regarding the importance of maintaining proper oral health, access to the dental health services have led to an increased demand to seek dental health care. These factors have contributed for increase work load on the dental health care providers. Moreover; inappropriate postures while treating the dental patients and injudicious working hours might lead to multiple occupational hazards among dental health care providers

Work-related musculoskeletal disorders (WRMSD) are problems of the musculoskeletal system that significantly cost workplace problems thus affecting occupational health, productivity and career of the working population. 55-93\% of dental professionals (dentist, dental hygienist and dental auxiliaries) experience WMSDs with highest risk among elderly subjects and women. Spine, shoulder, elbows and hands are the most likely area of the body to be stressed and suffer. ${ }^{3}$ There is a high prevalence of non-specific lower back and cervical (55\% and 38.5\% respectively) WMSDs among dentists, which were well correlated with the duration of work, posture while operating. ${ }^{4}$ The prevalence of general musculoskeletal pain range between $64 \%-93 \%{ }^{5}$ The most common cause of ill health retirement among dentist has been reported to be due to musculoskeletal disorders $(55 \%){ }^{6}$ 
The importance of best ergonomic working principles should be taught to the budding dental graduates at the dental colleges and should be incorporated in the curriculum, unfortunately in India a very little importance is given to this increasing problem.

Contradicting reports are seen in literature regarding the knowledge, attitude and behavior of dentists towards ergonomics across world and very sparse data is available in India, this provided an impetus to assess the dentists KAB towards ergonomics in Dhule Maharastra.

\section{Materials And Methods}

A set of closed ended questions were prepared to collect the relevant information pertaining to our study. Questions were related to assess the knowledge about ergonomics and work related musculo-skeletal disorders. Type of clinical practice, leisure activities, activities between successive visiting patients, Dentists working position, number of working hours, musculo-skeletal pathology, location of pain, consequence of pain, characteristics of dental chair, collaboration of dental assistant were included. Ethical clearance was obtained from the institutional ethical review board.

Questionnaires were tested for its feasibility; pilot study was conducted before the start of the main study and all the short comings were addressed. The total sample consisted of 40 males and 15 females, The Dentists were contacted to complete the questionnaire during their free hours, and Informed consent was obtained after explaining the aim and objectives of the study.

\section{Results}

In the present study, Males were $70 \%$ and females were $30 \%$. Majority of dental practioners were in the age group of 24- 40\% (55\%). Majority of dentist (53.5\%) worked for about 6-8 hours While 30.9\% dentist worked for 4-6 hours. Regarding the working position, majority of dental practioners $(45.4 \%)$ declared that they adopt sitting position and combination of sitting and standing position (43.6\%) (Table $3 \& 4$ ).

Around 82 - 84\% MDS Graduates had better knowledge and attitude towards ergonomic working postures and position, surprisingly, 46- $49 \%$ had adopted adequate working postures compared to the BDS Graduates. It was seen 34-66\% dentist didn't adapt adequate ergonomic behavior. $(\mathrm{p}<0.05)$ (Table 2)

The dental practioners indicated musculoskeletal disorders located in the back region $52.7 \%$, the Neck $27.4 \%$, the shoulder $12.7 \%$ and forearm and wrist region $3.6 \%$. It was seen only $3.6 \%$ didn't have MSD Symptoms. (Fig 1)

TABLE 1: Distribution of the study subjects based on Age, Gender and Qualification.

\begin{tabular}{|c|l|c|c|c|c|c|}
\hline \multirow{2}{*}{} & \multirow{2}{*}{ Total } & \multicolumn{3}{|c|}{ Age Groups } & \multicolumn{2}{c|}{ Qualification } \\
\cline { 3 - 6 } & 40 & $24-30$ YEARS & $31-40$ YEARS & $>40$ YEARS & MDS & BDS \\
\hline Males & 40 & $17(43 \%)$ & $13(33 \%)$ & $10(24 \%)$ & $16(28 \%)$ & $24(42 \%)$ \\
\hline Females & 15 & $2(11 \%)$ & $12(12 \%)$ & $1(16 \%)$ & $8(16 \%)$ & $7(14 \%)$ \\
\hline
\end{tabular}

TABLE 2: Distribution of subjects based on the opinion towards Knowledge, Attitude \&Behavior

\begin{tabular}{|c|c|c|c|c|c|c|c|c|}
\hline \multirow{2}{*}{ GENDER } & \multirow{2}{*}{ QUALIFICATION } & \multirow[t]{2}{*}{$\begin{array}{l}\text { TOTAL } \\
\text { NO. }\end{array}$} & \multirow{2}{*}{\multicolumn{2}{|c|}{$\begin{array}{l}\text { KNOWLEDGE } \\
\text { NO }\end{array}$}} & \multicolumn{2}{|c|}{ ATTITUDE } & \multicolumn{2}{|c|}{ BEHAVIOR } \\
\hline & & & & & $+\mathrm{VE}$ & $-\mathrm{VE}$ & $+\mathrm{VE}$ & $-\mathrm{VE}$ \\
\hline \multirow[b]{2}{*}{ MALES } & MDS & 16 & $82.20 \%$ & $17.70 \%$ & $87.23 \%$ & $22.27 \%$ & $49 \%$ & $51 \%$ \\
\hline & BDS & 24 & $71.20 \%$ & $29 \%$ & $76.00 \%$ & $24 \%$ & $36 \%$ & $64 \%$ \\
\hline \multirow{2}{*}{ FEMALES } & MDS & 8 & $84 \%$ & $16 \%$ & $87 \%$ & $23 \%$ & $46 \%$ & $34 \%$ \\
\hline & BDS & 7 & $64 \%$ & $36 \%$ & $75 \%$ & $25 \%$ & $34 \%$ & $66 \%$ \\
\hline
\end{tabular}
$\mathrm{p}<0.05$

TABLE 3: Distribution of the subjects on the basis of Working Hours.

\begin{tabular}{|c|c|}
\hline WORKING HOURS & INDIVIDUALS \% \\
\hline 4-6 HOURS & $17(30.9 \%)$ \\
\hline 6-8 HOURS & $30 \quad(53.7 \%)$ \\
\hline$>8$ HOURS & $8 \quad(14.5 \%)$ \\
\hline
\end{tabular}

TABLE 4: Distribution of the subjects on the basis of Type of Dentistry

\begin{tabular}{|c|c|}
\hline POSITIONS & PERCENTAGE \\
\hline SITTING & $25(45.4 \%)$ \\
\hline STANDING & $6(11.0 \%)$ \\
\hline BOTH & $24(43.6 \%)$ \\
\hline
\end{tabular}


Fig1: Pain distribution in different locations of a Body

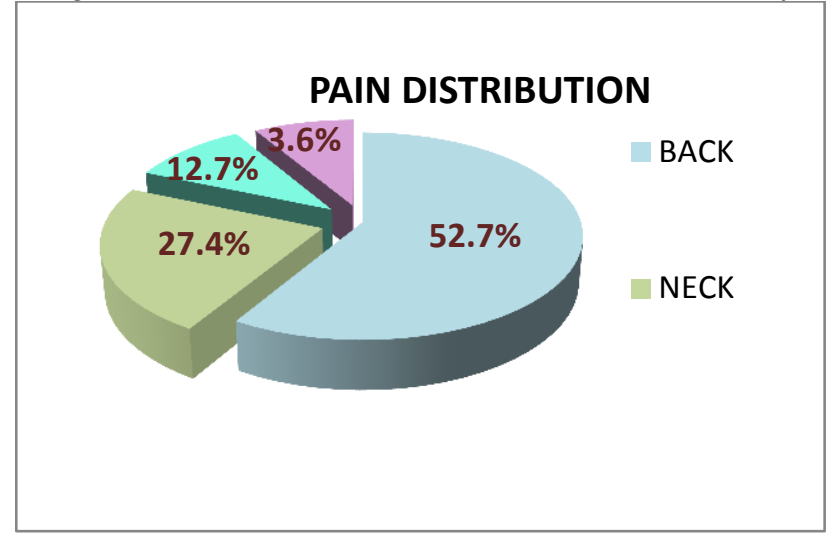

IV. Discussion:

Posture reflects the position that an individual maintains in space via his bone -muscle-skeletal system. ${ }^{7}$ Maintaining good postures helps the body to lower the energy expenditure, improves organ function and also helps to protect the individual against any occupational hazard. ${ }^{8}$ The result of the present study reflected a lack of adequate ergonomic posture, while providing oral health care. It was observed MDS Graduate, had sufficient knowledge, attitude regarding the importance of proper working postures and position during providing treatment, but didn't result in the desired behavior $51 \% ;(\mathrm{p}<0.05)$ this indicates that knowledge had not motivated sufficiently to adapt ergonomic principles, however female MDS Graduates had adequate behavior towards ergonomically working position.(table 2) Female dentist face unique musculoskeletal problems \& inherent gender differences that may place them at higher risk for occupational pain \& injury than their male counter parts.

Female dentist may take pre-emptive action and adopt ergonomic principles while working to reduce the risk of developing musculoskeletal disorders ${ }^{2}$ this was evident in the present study with female MDS graduates (46\%) compiling to dental ergonomics than the BDS Graduates. The present study fails to explain the reasons behind the non adaptability of ergonomic principles in their daily practice, demands the further studies to understand the gap existing between knowledge, awareness not being translated to the desired behavior. There is a strong correlation between the type of task performed by the dentists \& the development of musculoskeletal symptoms. ${ }^{9}$ Around $34-66 \%$ of dental practitioners are at risk for developing work related musculoskeletal disorders. (Table 2) The total number of hours spent for work is directly related to the severity of musculoskeletal disorders. Majority of the Dentists were not inclined towards the regular physical Exercises.

Most of the dentists in the present study, relate their symptoms to awkward posture adapted during working hours. Ergonomically designed dental instruments may help reduce the prevalence of musculoskeletal disorders among Dental practitioners. The primary objective of dental ergonomics is the prevention of work related musculoskeletal disorders. ${ }^{4,10}$ this calls for immediate need for the dentists' education and motivation about the importance of adopting ergonomic principles for improving the quality of life.

In this study the most prevalent WMSDs were reported at the back, neck and shoulder; similar findings were found in the study conducted by Sharma \& Golccha. ${ }^{11}$ however majority of dentist didn't sought the medical expert advice or treatment for the same, this clearly shows the lack of positive attitude and behavior among the dentist to address the problems at the initial stages and thus not giving importance to prevent the further complications. To overcome this attitude, dentists should be encouraged, motivated and updated regarding the importance of dental ergonomics and applying it to daily practice. Moreover, the prevalence and severity of various musculoskeletal disorders decreases by performing regular exercises. ${ }^{11}$

This study gives an insight into the level of awareness among Indian dentists regarding the importance of maintaining the proper posture and regular physical activity. The physical inactivity among dentist seems to put them at risk for the occurrence of WMSDs. WMSDs are the major reasons leading for loss of work efficiency as well as early ill health retirement among dentists. ${ }^{6}$ Probably, lack of exposure during graduation, towards the dental ergonomics principles, poor understanding of ergonomic theory; coupled with other various factors places the dental practioners at higher risk of work related musculoskeletal disorders. In this sense, it is wise to inculcate the ergonomics in the study curriculum for better understanding and learning as well as for the assessment .The dental profession should make an effort to create awareness about the ergonomics; also the dental students should be taught during graduation the importance of dental ergonomic principles. The acquisition of ergonomics knowledge can occur at any time however early assimilation of knowledge and internalization of dental ergonomic principles might prevent their suffering from work related musculoskeletal disorders. 


\section{Conclusion}

After studying the dentists' perception toward ergonomics among all the practicing dentists of Dhule city, it is revealed that majority of the dentists are having knowledge and had a positive attitude towards ergonomics but their behavior is not satisfactory. So there is the need for strong implementation of ergonomics in day to day life. There is a need to motivate and promote among dentists towards the importance of ergonomics. Ergonomically designed instruments should be used. The goal of ergonomic is to establish a safe, healthy and comfortable working environment, thereby preventing health problems and improving work efficiency. So that dentists can enjoy a healthy life style and enable them to have quality of life.

\section{References}

[1]. Dul J,Weerdmeester B. Practice ergonomic.Sao Paulo: edgar Blucher,2004.

[2]. Castro SL,Figlioli MD.Ergonomics applied to dentistry: evaluation of posture and work positions of the dentist and the assistant handed dentistry in restorative procedures.JBC J Bras Clin Estet Odontol 1999;3: 56-62

[3]. Sartprio F,Vercelli S,Ferriero G,D'Angelo F,Migliario M,Franchignoni M.Work-related musculoskeletal diseases in dental professionals. Prevalence and risk factors. Ital Med Lav Ergon 2005;27(2):165-9

[4]. Ratzon N,Yaros M,Mizlik A,Kanner T.Musculoskeletal symptoms among dentists in relation to work posture. Work 2000;15:153-8

[5]. Hayes M,Crockrell D,Smith DR.A Systematic review of musculoskeletal disorders among dental professionals.Int J dent Hug 2009;7:159-65

[6]. Brown J,Burke FJ,Macdonald EB,Gilmour H,Hill KB,Morris AJ,et al.Dental practioners and ill health retirement causes, outcomes and re-employement.Br Dent J 2010;209:E7

[7]. Wilson EL,Madigan ML,Davidson BS,Nussbaum MA. Postural strategy changes with fatigue of the lumbar extensor muscles. Gait Posture 2006;23:348-54

[8]. Moffat M,Vickery S. Manual of maintenance and postural re-education. Porto Alegreartmed,2002

[9]. Thornton LJ,Barr AE,Stuart-Buttle c,Gaughan JP,Wilson ER,Jackson AD, et al . Perceived musculoskeletal symptoms among dental students in the clinic work environment. Ergonomics .2008;51:573-86

[10]. Nermin Y. Musculoskeletal disorders and dental practice. Part 1.General information-terminology,aetiology,work-relatedness, magnitude of the problem, and prevention.Int dent J 2006; 56:359-66

[11]. Sharma P,Golcha V.Awareness among Indian dentist regarding the role of physical activity in prevention of work related musculoskeletal disorders. Indian J Dent Res 2011;22:381-4 